\title{
Estimation of cardiovascular and respiratory diseases attributed to PM10 using AirQ model in Urmia during 2011-2017
}

\author{
Leily Sokoty $^{1}$, Majid Kermani ${ }^{2,3}$, Leila Janani ${ }^{4}$, Mohsen Dowlat ${ }^{5}$, Babak Hassanlouei ${ }^{1,6}$, Shahnaz Rimaz ${ }^{* 1,2,7(\mathbb{D})}$
}

Received: 16 Aug 2018

Published: 10 Jun 2020

\section{Abstract}

Background: Quantification of the attributed effects of air pollution determines the impact of air pollutants on the community and shows the critical condition of air quality.

This study aimed to quantify and estimate the cardiovascular and respiratory diseases attributed to PM10 in Urmia during 2011-2016.

Methods: In this descriptive-analytic study, at first, hourly data of pollutant PM10 concentrations were received from air pollutants station located in the Department of Environmental Protection. The data were evaluated using AirQ2.2.3 software after primary and secondary processes and filtering.

Results: The results showed that the mean annual concentration of PM10 during 2011-2016 was 88.66, 92.45, 81.22, 78.38, 113.78, and $92.67 \mu \mathrm{g} / \mathrm{m} 3$, respectively. The number of hospitalized cases due to respiratory diseases attributed to PM10 in this period was 486 , $525,459,453,684$, and 552, respectively, and the number of cases due to cardiovascular diseases was 188, 203, 177, 175, 263, and 213, respectively.

Conclusion: Considering the attributed health effects of PM10, the necessary measures should be taken to identify the causative agents and to understand the mechanisms of these processes and correct them.

Keywords: Air Q model, PM10 particles, Cardiorespiratory diseases, Urmia

Conflicts of Interest: None declared

Funding: This work was funded by Iran University of Medical Sciences (Grant number: 32421).

\section{*This work has been published under CC BY-NC-SA 1.0 license. \\ Copyright $\odot$ Iran University of Medical Sciences}

Cite this article as: Sokoty L, Kermani M, Janani L, Dowlat M, Hassanlouei B, Rimaz Sh. Estimation of cardiovascular and respiratory diseases attributed to PM10 using AirQ model in Urmia during 2011-2017. Med J Islam Repub Iran. 2020 (10 Jun);34:60. https://doi.org/10.47176/mjiri.34.60

\section{Introduction}

Air pollution is not a new phenomenon and is blended with modern life. In fact, it is the product of urban construction and the remaining wastes which are derived from such activities as the production of goods, transportation, heating, recreation, and human work (1). In addition to environmental degradation and economic losses, air pollution is

Corresponding author: Dr Shahnaz Rimaz, rimaz.sh@iums.ac.ir

Department of Epidemiology, School of Public Health, Iran of University of Medical Sciences, Tehran, Iran

2. Research Center for Environmental Health Technology, Iran University of Medical Sciences, Tehran, Iran

3. Department of Environmental Health Engineering, School of Public Health, Iran University of Medical Sciences, Tehran, Iran

4. Department of Biostatistics, School of Public Health, Iran University of Medical Sciences, Tehran, Iran

5. School of Health Management and Information Sciences, Iran University of Medical Sciences, Tehran, Iran

6. Student Research Committee, Iran University of Medical Sciences, Tehran, Iran

7. Radiation Biology Research Center, Iran University of Medical Sciences, Tehran, Iran one of the 10 most important causes of mortality worldwide, with death rates from 800000 in the year 2000 to 1.3 million in the year 2010 (2). Previous studies have shown that photochemical particles and photochemical pollutants of urban traffic may have adverse effects on humans, although they are lower than the maximum level (3).

Air pollution can cause some acute and chronic health

\section{$\uparrow$ What is "already known" in this topic:}

Air pollution has imposed serious problems on the society's health and environment in Urmia. In Urmia, the mean annual concentration of air pollutants is more than the standard level, and air pollution leads to more hospitalization due to cardiovascular and respiratory diseases.

\section{$\rightarrow$ What this article adds:}

No assessment has been done on the effects of air pollution on the health of Urmia residents in recent years. In this study, AirQ software based on the WHO approach was used. The results of air pollution studies can help policymakers to reduce air pollution. 
problems such as cardiovascular and respiratory diseases and death (4-7).

Suspended particles less than 10 microns are considered to be major contaminants for public health (8). Also, these particles are the main source of concern for air quality due to combustion, traffic, and industrial activities $(9,10)$. Some studies have provided strong evidences that suspended particles are associated with a high rate of mortality in long-term and short-term exposures (11), so that shortterm exposure to PM10 causes lung irritation, respiratory function, coughing, and respiratory responses (4).

In the results of studies conducted by Goodarzi et al, it was found that about $4 \%$ of all cardiovascular and respiratory deaths in Tehran have been attributed to concentrations of more than $20 \mu \mathrm{g} / \mathrm{m}^{3}$ of PM10 (12). Another study in Mecca have shown that the risk to humans exposed to suspended particles with an emphasis on respiratory diseases is roughly increasing (13). A study by Chen et al showed a significant relationship between suspended matter with a diameter of less than 10 microns in the traffic-intensive areas of Australia and the number of patients referring to the emergency departments for respiratory problems (14). This research was conducted to study the air quality of Urmia. The city faces the problem of air pollution due to urbanization, increasing number of cars, industrialization, increasing factories, and its special geographical conditions.

To illustrate the extent to which people living in a region are exposed to pollutants, the effects of pollutants need to be quantified. AirQ2.2.3 software provides short-term effects of air pollutants and predicts the health of airborne contaminants (15).

The nature of the effect of air pollution (acute and chronic) and the type of exposure (short-term or long-term) are effective in selecting the type of study (16). Management plans to control air pollution in large cities are considered to be the most important strategies that use precise data sources about environmental conditions to determine all effects of air pollution on human health $(17,18)$. Considering that the health effects of air pollution have not been scientifically investigated, we used AirQ2.2.3 software in this study to determine the short-term effects of suspended particles and their health-related problems in Urmia. Therefore, this study was aimed to quantify and estimate the cardiovascular and respiratory diseases attributed to PM10 in Urmia during 2011-2016.

\section{Methods}

This cross sectional study was conducted in Urmia, a metropolitan city in the center of West Azerbaijan province and in the northwest of Iran. According to the last census done in 2017, Urmia is the 10th most populated city in Iran and the second most populated city in the northwest of Iran (Fig. 1). Required data were collected from the Department of Environmental and Meteorological Organization of Urmia, and according to the criteria stated by the World Health Organization (WHO). Also, the number of stations with valid data was identified to determine the credibility.

According to the criteria stated by the WHO, the number of stations with valid data was identified. Therefore, the registered data of all stations were filtered to assess data validity, according to the WHO standards. To delete invalid data during the primary filtering, the ratio of warm seasons/cold seasons needed to be less than 2 . Also, $50 \%$ of the data needed to have enough validity to estimate the daily mean (19).

Iran Meteorological Organization provided daily values of humidity and temperature mean. After preparing the input file, the following raw data were entered into the AirQ software: (1) primary processing: elimination and time alignment to calculate the total mean of each pollutant; (2) secondary processing: writing codes, calculating daily mean, eg, extracting the required statistical indices such as the annual mean, mean warm season, mean cold season, 98th percentile score, annual maximum and maximum warm and cold seasons as presented in (Table 1); (3) primary filtering: temperature and pressure correction and conformity of units with the model; (4) secondary filtering: pollutants concentration, required parameters, etc.); and (5) some quantitative data. AirQ software, a reliable and valid tool, was developed by WHO to evaluate the potential of short-term effects of exposure on people living in a specific geographical area during a period of time (19). Estimation of the adverse effect of air pollution on health is correlated to the volume of air pollutants in AirQ. Iran Statistics Center presented the population at risk from air pollution (Fig. 2).

Considering that the input data units should be in volumetric weight, PM10 was recorded as $\mu \mathrm{g} / \mathrm{m}^{3}$. Subsequently, the results of the data mining in the software were derived from the results of the examinations and the number of admitted patients suffering from cardiovascular and

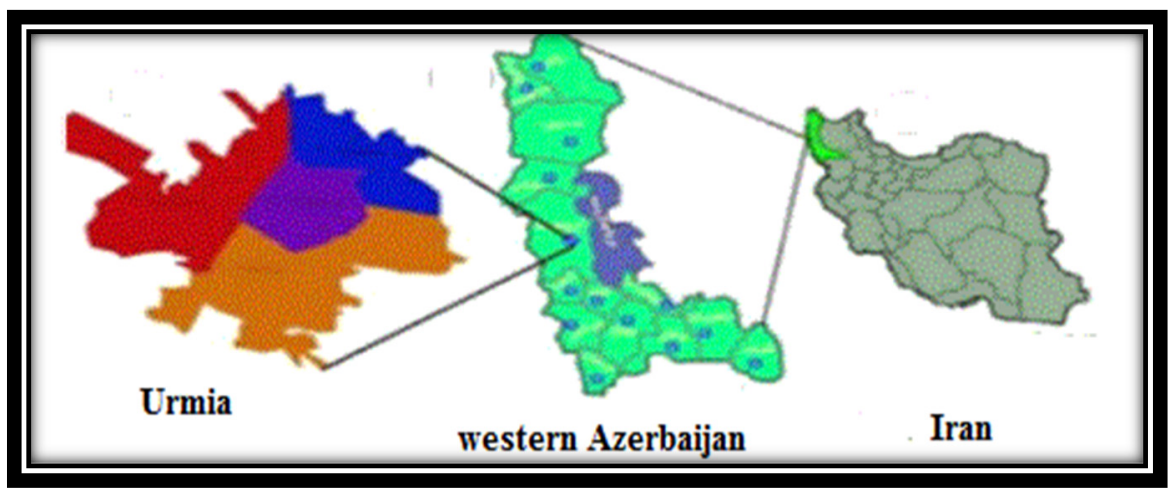

Fig. 1. Geographic situation of Urmia in Iran (20) 
Table 1. Indicators to estimate the effects of PM10 and the mean annual concentration $\left(\mu \mathrm{g} / \mathrm{m}^{3}\right)$ from 2012 to 2017

\begin{tabular}{|c|c|c|c|c|c|c|}
\hline Parameter & 2012 & 2013 & 2014 & 2015 & 2016 & 2017 \\
\hline Annual average & 88.60 & 92.45 & 81.02 & 78.33 & 113.83 & 92.67 \\
\hline Cold season average & 72.19 & 87.99 & 82.63 & 26.60 & 103.47 & 95.53 \\
\hline Warm season average & 104.04 & 96.76 & 79.35 & 82.39 & 124.14 & 89.94 \\
\hline Annual 98th percentile & 239.86 & 226.05 & 182.99 & 167.17 & 259.03 & 202.53 \\
\hline Annual maximum & 931.15 & 869.54 & 737.30 & 344.61 & 594.61 & 356.86 \\
\hline Cold season maximum & 288.23 & 227.73 & 195.00 & 250.52 & 350.62 & 237.05 \\
\hline Warm season maximum & 931.15 & 869.54 & 737.30 & 344.61 & 594.61 & 356.86 \\
\hline
\end{tabular}

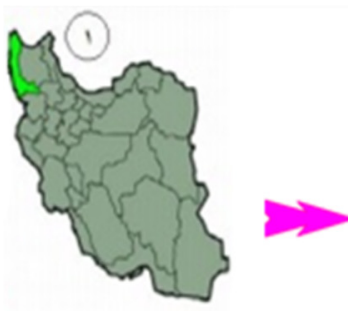

Air Quality Monitoring Station

Fig. 2. Schematic view of performed process in this study (Draw writers)

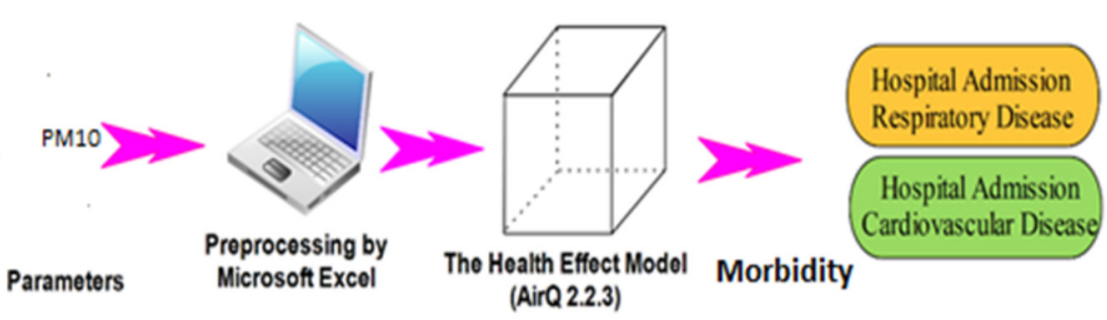

(AirQ 2.2.3) respiratory diseases. To calculate the health effects and outcomes, the number of hypotheses was replaced with personal estimates of relative risk and baseline incidence (95\% confidence intervals) from regional and national epidemiological studies, which were specific to Iran and were entered into AirQ2.2.3 software $(21,22)$. The AirQ model, relative risk, and baseline incidence are main parameters in epidemiology studies $(6,7)$.

To estimate the effects of exposure to specific air pollutants on the people's health in a certain area or time, the AirQ model can be applied using attributable proportion (AP). Indeed, AP is considered as a fraction of the health outcome in a defined population exposed to air pollutants. AP is calculated based on the following formulae (23).

$\mathrm{AP}=\operatorname{SUM}\{(\mathrm{RR}(\mathrm{c})-1) \mathrm{p}(\mathrm{c})\} / \mathrm{SUM}(\mathrm{RR}(\mathrm{c}) \mathrm{p}(\mathrm{c}))(1)$.

AP shows a proven causal relationship between health outcome and known exposure without major confounding effects. RR indicates the relative risk and $\mathrm{P}(\mathrm{c})$ the population at risk. RR is simply calculated using the following formula:

$\mathrm{RR}=($ Disease with exposure $) /($ Disease without exposure) (2).

While the baseline frequency for the outcome of interest is determined in the certain population, the rate attributable to the exposure is calculated using the following formula: $\mathrm{IE}=\mathrm{I}^{*} \mathrm{AP}(3)$.

IE is the rate of the health outcome attributable to the exposure and I the baseline frequency of the health outcome in a given population. Considering the population, the frequency of patients attributable to the exposure is calculated using the following formula: $\mathrm{NE}=\mathrm{IE}^{*} \mathrm{~N}(4)$.

$\mathrm{NE}$ is the frequency of patients attributed to the exposure of interest and $\mathrm{N}$ refers to the population size. Following the data analysis through AirQ, the proportion attributable to PM10 and the excess patients of emergency hospitalizations were calculated.

\section{Results}

The results of this study covers the statistical parameter of the concentration of PM10 during 2011-2016 in Urmia. Initially, after verifying the data according to WHO standards, they were obtained from the Department of Environment of West Azerbaijan province. Only one of the 4 stations located in Urmia had valid data for analysis.

Relative risk and baseline incidence based on previous

Table 2. Relative risk, component, and cases attributed to PM10 for emergency hospitalization due to cardiovascular disease

\begin{tabular}{|c|c|c|c|c|c|c|}
\hline \multicolumn{7}{|c|}{ Relative risk (RR) as per every $10 \mu \mathrm{g} / \mathrm{m}^{3}$} \\
\hline \multicolumn{7}{|c|}{ Estimate indicator } \\
\hline & \multicolumn{2}{|c|}{ Lower limit } & \multicolumn{2}{|c|}{ Central limit } & \multicolumn{2}{|c|}{ Upper limit } \\
\hline & \multicolumn{2}{|r|}{1.006} & \multicolumn{2}{|c|}{1.009} & \multicolumn{2}{|c|}{1.013} \\
\hline Year & $\begin{array}{c}\text { Attributed } \\
\text { component } \\
\text { estimate }(\%)\end{array}$ & $\begin{array}{c}\text { Number of attributed } \\
\text { cases } \\
\text { (Person) }\end{array}$ & $\begin{array}{c}\text { Attributed } \\
\text { component estimate } \\
(\%)\end{array}$ & $\begin{array}{c}\text { Number of } \\
\text { attributed cases } \\
\text { (Person) }\end{array}$ & $\begin{array}{c}\text { Attributed } \\
\text { component } \\
\text { estimate }(\%)\end{array}$ & $\begin{array}{c}\text { Number of } \\
\text { attributed cases } \\
\text { (Person) }\end{array}$ \\
\hline 2012 & 4.4 & 128 & 6.4 & 188 & 9.7 & 264 \\
\hline 2013 & 4.7 & 138 & 6.8 & 203 & 9.7 & 284 \\
\hline 2014 & 4.0 & 120 & 5.9 & 117 & 8.3 & 250 \\
\hline 2015 & 3.9 & 119 & 5.8 & 175 & 8.1 & 264 \\
\hline 2016 & 5.9 & 181 & 8.6 & 263 & 12 & 362 \\
\hline 2017 & 4.7 & 145 & 6.9 & 213 & 9.7 & 299 \\
\hline 2012-2017 & & 832 & & 1219 & & 1723 \\
\hline
\end{tabular}


studies obtained for admission to hospitals due to cardiovascular disease $(\mathrm{RR}=1.009, \mathrm{CI}$ : 1.006-1.013, $\mathrm{n}=436)$ and admission to hospitals due to respiratory disease $(\mathrm{RR}=1.008, \mathrm{CI}: 1.004-1.011, \mathrm{n}=1260)$ entered into the AirQ software $(21,22)$. In fact, the increase in every 10 $\mu \mathrm{g} / \mathrm{m} 3$ of PM10 will increase the risk of admission due to respiratory disease and cardiovascular disease by up to $0.8 \%$ and $0.9 \%$, respectively.

Based on the results of AirQ2.2.3 software, the number of additional cases and associated items for the total number of cases of respiratory and cardiovascular diseases was estimated (Tables 2 and 3).

The number of cases attributed to PM10 based on the central limit of relative risk in 6 years was 486, 525, 459, $453,684,559$, and 552 due to respiratory disease, with attributable fraction of 5.7, 6.1, 5.3, 5.2, 7.7, 6.2; also, 188, $203,177,175,263$, and 213 cases were due to cardiovascular disease, with attributable fraction of $6.4,6.8,5.9,5.8$, 8.6 and 6.9 , respectively.

In the present study, the concentration of pm10 in Urmia was analyzed and the health effects attributed to air pollution were assessed. The Charts 1 and 2 show the exposure

Table 3. Relative risk, component, and cases attributed to PM10 for emergency hospitalization due to respiratory disease

\begin{tabular}{|c|c|c|c|c|c|c|}
\hline \multicolumn{7}{|c|}{ Relative risk (RR) as per every $10 \mu \mathrm{g} / \mathrm{m}^{3}$} \\
\hline \multicolumn{7}{|c|}{ Estimate indicator } \\
\hline \multirow[b]{3}{*}{ Year } & \multirow[b]{3}{*}{$\begin{array}{c}\text { Attributed } \\
\text { component } \\
\text { estimate }(\%)\end{array}$} & Lower limit & \multicolumn{2}{|c|}{ Central limit } & \multicolumn{2}{|c|}{ Upper limit } \\
\hline & & 1.004 & \multicolumn{2}{|c|}{1.008} & \multicolumn{2}{|r|}{1.011} \\
\hline & & $\begin{array}{c}\text { Number of } \\
\text { attributed cases } \\
\text { (Person) }\end{array}$ & $\begin{array}{c}\text { Attributed } \\
\text { component } \\
\text { estimate } \\
(\%)\end{array}$ & $\begin{array}{l}\text { Number of } \\
\text { attributed } \\
\text { cases } \\
\text { (Person) }\end{array}$ & $\begin{array}{l}\text { Attributed } \\
\text { component } \\
\text { estimate } \\
(\%)\end{array}$ & $\begin{array}{c}\text { Number of attributed } \\
\text { cases } \\
\text { (Person) }\end{array}$ \\
\hline 2012 & 3.5 & 299 & 5.7 & 486 & 7.9 & 666 \\
\hline 2013 & 3.8 & 323 & 6.1 & 525 & 8.4 & 718 \\
\hline 2014 & 3.2 & 281 & 5.3 & 459 & 7.3 & 629 \\
\hline 2015 & 3.1 & 277 & 5.2 & 453 & 7.1 & 621 \\
\hline 2016 & 4.8 & 423 & 7.7 & 684 & 10.5 & 928 \\
\hline 2017 & 3.8 & 340 & 6.2 & 552 & 8.4 & 755 \\
\hline $2012-2017$ & & 1943 & & 3159 & & 4317 \\
\hline
\end{tabular}

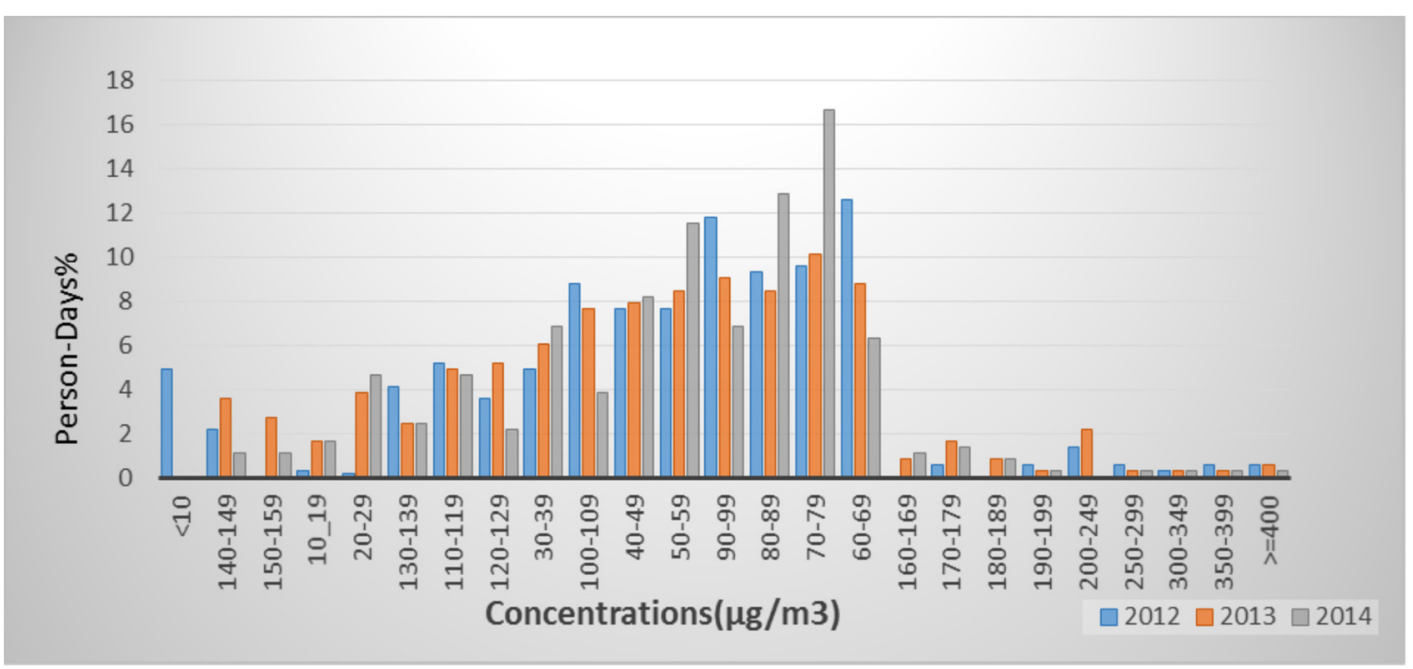

Chart 1. The percentages of the days that residents of Urmia encountered with various amounts of PM10 during 2012-2014

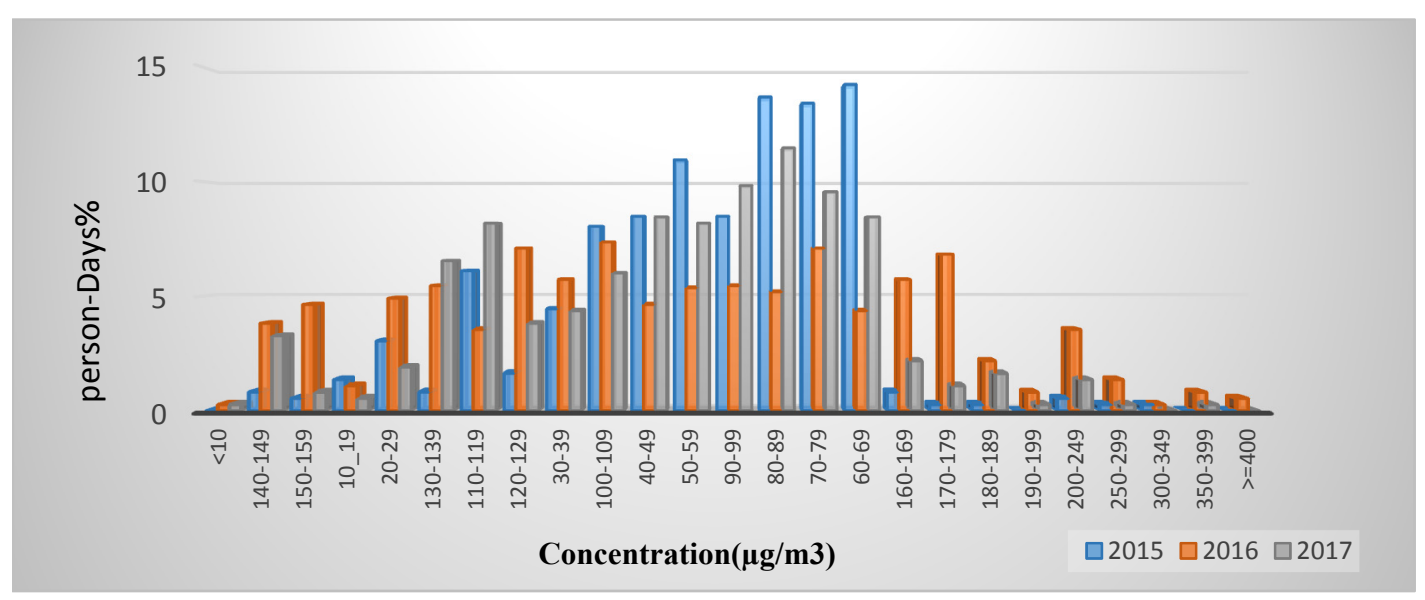

Chart 2. The percentages of the days with various amounts of PM10 during 2015-2017 
Table 4. Standards and guidelines for the mean ambient particulate concentration $\left(\mu \mathrm{g} / \mathrm{m}^{3}\right)$

\begin{tabular}{|c|c|c|c|}
\hline Standard or Guideline PM10 & $\begin{array}{c}\text { Annual Mean } \\
\left(\mu \mathrm{g} / \mathrm{m}^{3}\right)\end{array}$ & Year & $\begin{array}{c}\text { Concentration PM10 } \\
\left(\mu \mathrm{g} / \mathrm{m}^{3}\right)\end{array}$ \\
\hline WHO Guidelines (WHO 2005) & 20 & 2012 & 4.43 \\
\hline National Ambient Air Quality Standards (NAAQS) & 50 & 2013 & 4.62 \\
\hline Iran National Standard & 20 & 2014 & 4.05 \\
\hline State of California & 20 & 2015 & 3.91 \\
\hline Other European Countries & 20 & 2016 & 5.69 \\
\hline USA Federal Standard & - & 2017 & 4.63 \\
\hline
\end{tabular}

*Comparison of the mean annual concentration of PM10 with Iran national standards in Urmia during 2011-2016.

of PM10 at central limit relative risk for 6 years. The average amount of PM10 concentration in 2015 and 2016 was 2.27-1.85 times higher than the limit compared to the rest. According to the estimated component and the number of hospital admissions attributed to PM10 in Urmia, it can be stated that this city has unfavorable conditions, which could be the result of the continuity of days with a higher concentration of suspended particles or a higher mean of this contaminant (Table 4).

\section{Discussion}

This study used the AirQ model to assess the impact of short-term exposure to PM10 concentrations on human health.

According to Table 1, the mean concentration of PM10 in cold seasons was more than the warm seasons in 2014 and 2017. However, it has been higher in the warm season in 2012, 2013, 2015, and 2016. The results of this study showed that the number of hospitalizations due to respiratory disease was $8404,8505,8611,8706,8807$, and 8908 , so that $486,535,459,453,684$, and 552 were attributed to PM10 during 2011-2016. Also, the number of hospitalization due to cardiovascular disease was 2894, 2943, 2967, 3012, 3039, 3074, and 188, 203, 177, 175, 263, and 213 were attributed to PM10.

In total, the number of admitted cases attributedto PM10 due to respiratory and cardiovascular disease was 3159 and 1219 cases, respectively. Assessing a direct relationship between contact with various particles concentrations and their effects on human health is quite difficult due to the interaction between atmospheric pollutants and other components. However, the AirQ model is one of the most promising models of the WHO that can be utilized to estimate the effects of air pollutants on human's health.

According to the study performed by Kermani et al, in which the health effects of exposure to airborne particulate matter in Tehran from 2004-2015 was evaluated, the total hospitalization cases due to cardiovascular and respiratory diseases were 20990 and 54352 cases, respectively, which were attributable to PM10. Finally, they concluded that health effects of exposure to suspended particles in Tehran was very severe and increased the mortality and cardiovascular and respiratory diseases in the citizens (24).

According to the study by Kamarehie et al, on the morbidity and mortality attributed to PM10 and PM2.5 exposure in city of Bukan during 2015-2016, the total mortality rates were 49.8 , and 33.3 deaths were attributed to PM2.5 and PM10, respectively. Also, $3.79 \%$ of the total mortality was related to PM10. In Bukan, cardiovascular mortality accounts for $2 \%$ of total deaths. The Air Quality model was used to predict the deaths of 92.2 people dealing with hospitalization due to respiratory disease (25).

In a study of Kianisadr et al, on the air quality index $\left(\mathrm{PM}_{10}\right.$ and $\left.\mathrm{PM}_{2.5}\right)$ by Arc-GIS in city of Khorramabad, the results indicated that continuous dust storms, particularly in recent years, led to unhealthy air condition in Khorramabad that can adversely affect the health of residents (26). In the study performed by Kosha et al, there was an important linkage between hospitalization due to respiratory and cardiovascular diseases and particles concentration in Tabriz. They showed that high concentration of the particles increased the frequency of hospitalization due to respiratory and cardiovascular diseases (27).

According to the study of Khorsandi et al, in 2014 in Urmia, the annual mean of PM10 was 83 micrograms in cubic meters and hospitalized patients due to respiratory and cardiovascular diseases were 482 and 187 , respectively, determined by the AirQ2.2.3 model (28). While in the present study, it was 459 cases due to respiratory and 177 due to cardiovascular cases in 2013. This difference may be due to the numerical difference in geographic distribution, population at risk (recorded population census, taking into account the growth rate) or the difference in the mean daily pollutant record. According to another study of Khorsandi et al in 2011, suspended particles, CO and so2, had the highest contribution as the pollutants responsible for air pollution in Urmia in nonstandard conditions (2).

Similar studies have shown that the effects of PM10 on total mortality were responsible for 2194 deaths in Tehran in 2012 (22). Other studies have shown that the highest number of deaths caused by air pollution was related to PM10 particles (100 deaths) (29).

A survey conducted in a number of American and European cities and in a number of Asian countries showed that short-term contact with suspended particles of less than 10 microns in developed and non-developed countries is in contradiction with Iran (30-32).

In a study by Nadafi et al, entitled "quantifying the health effects of air pollutants in Tehran in 2012", the results showed that the highest share of health effects attributed to suspended particles was 2.5 and 10 microns (22). This software does not consider a causal relationship among the encounter and the message and the confounders (33).

One limitation of this study was exposure assessment, which shows the average exposure of the residents in Urmia. However, because the data used in this study were aggregate data, we could not interpret it at the individual level.

Urmia is exposed to particles due to neighboring with countries in the northwest. The increase in the number of 
vehicles in a cold weather causes the inversion of temperature. Therefore, air pollution in Urmia is considered as a serious problem and requires the attention of the policymakers to take preventive and control measures in this regard. Therefore, it is necessary to continuously monitor the air pollution indicators and take important measures to identify the effective factors.

To reduce the effects of air pollution, there is a need for plan development and collaboration among organizations and even neighboring countries.

The results of this study will be helpful if accompanied by political and economic regulations. Also, considering that air pollution causes mortality and that general health depends on various factors, including industry, engineering, and biostatistics, targeted education is required for environmentalists whose knowledge about new tools is not enough.

\section{Conclusion}

Overpopulation causes uncontrolled development of urban areas and more fossil fuels consumption leading to air pollution. Regarding the attributed health effects of PM10, the necessary measures should be taken to identify the causative mechanisms of these processes and to correct them. Thus, the policymakers, and specialists in the field of interest should focus on the reduction of air pollution.

\section{Acknowledgements}

This work was funded by Iran University of Medical Sciences (Grant number: 32421). The authors would like to thank the Environmental Protection Agency of Tehran and Air Quality Control Company for providing the data of pollutants 'concentrations.

\section{Conflict of Interests}

The authors declare that they have no competing interests.

\section{References}

1. Wark K, Warner CF, Davis WT. Air Pollution: Its Origin and Control. 3rd Edition, Addison Wesley Longman Inc., Menlo Park. 1998

.2 .Khorsandi H, Amini Tapok F, Cargar H, Mousavi Moughanjogi S. Study of Urmia city air quality according to the air quality index (AQI). Studies in Medical Sciences, Vet Res Forum. 2013;23(7):767-775.

3. Talbott EO, Rager JR, Benson S, Brink LA, Bilonick RA, Wu C. A case-crossover analysis of the impact of PM 2.5 on cardiovascular disease hospitalizations for selected CDC tracking. Environ Res. 2014;134:455-465.

4. Khaniabadi YO, Daryanoosh SM, Amrane A, Polosa R, Hopke PK, Goudarzi G, et al. Impact of Middle Eastern Dust storms on human health. Atmos Pollut Res. 2017;8(4):606-613.

5. Khaniabadi YO, Daryanoosh SM, Hopke PK, Ferrante M, De Marco A, Sicard P, et al. Acute myocardial infarction and COPD attributed to ambient $\mathrm{SO}_{2}$ in Iran. Environ Res. 2017;156:683-687.

6. Khaniabadi YO, Fanelli R, De Marco A, Daryanoosh SM, Kloog Itai, Ferrante M, et al Hospital admissions in Iran for cardiovascular and respiratory diseases attributed to the Middle Eastern Dust storms. Environ Sci Pollut Res. 2017;24(20):16860-16868.

7. Khaniabadi YO, Goudarzi G, Daryanoosh SM, Borgini A, Tittarelli A \& Alessandra De Marco. Exposure to PM10, $\mathrm{NO}_{2}$, and $\mathrm{O}_{3}$ and impacts on human health. Environ Sci Pollut Res. 2017;24(3):27812789.

8. Kermani M, Dowlati M, Jonidi Jafari A, Rezaei Kalantary R. Health risks attributed to particulate matter of 2.5 microns or less in Tehran air 2005-2015. J Kermanshah Uni Med Sci. 2016;20(3):99-105.
9.Molina MJ, Molina LT. Megacities and atmospheric pollution. J Air Waste Manag Assoc. 2004;54(6):644-680.

10. Watson JG. Visibility: Science and regulation. Journal of the Air \& Waste Management Association 2002. J Air Waste Manag Assoc. 2002;52(6):628-713.

11. Orru H, Maasikmets M, Lai T, Tamm T, Kaasik M, Kimmel V, et al. Health impacts of particulate matter in five major Estonian towns: main sources of exposure and local differences. Air Qual Atmos Health. 2011;4(3-4):247-258

12. Goudarzi G, Nadafi K, Mesdaghiniya A. Quantification of health effects of air pollution in Tehran and determining the impact of a comprehensive program to reduce air pollution in Tehran on the third axis. [Phd Thesis]. Tehran, Iran: Tehran University of Medical Sciences; 2007 (Persian)

13. Habeebullah T. Health impacts of PM10 using AirQ2. 2.3 model in Makkah. Beni Suef Uni J Basic Appl Sci. 2013;9:259-268.

14. Chen L, Mengersen K, Tong S. Spatiotemporal relationship between particle air pollution and respiratory emergency hospital admissions in Brisbane, Australia. Sci Total Environ. 2007;373(1):57-67.

15. Oliveri Conti G, Heibati B, Kloog I, Fiore M, Ferrante M. A review of AirQ Models and their papplications for forecasting the air pollution health outcomes. Environ Sci Pollut Res. 2017:1-20.

16. Qorbani M, Yunesian M. Study Designs in Air Pollution Epidemiology. Iran J Epidemiol. 2010;5(4):44-52

17. Arfaeinia H, Kermani M, Aghaei M, Bahrami Asl F, Karimzadeh S. Comparative investigation of health quality of air in Tehran, Isfahan and Shiraz metropolises in 2011-2012. J Health Field. 2014;1(4).

18. Kermani M, Bahrami Asl F, Aghaei M, Arfaeinia H, Karimzadeh $\mathrm{S}$, Shahsavani A. Comparative investigation of air quality index (AQI) for six industrial cities of Iran. Vet Res Forum. 2014;25(9):810-819.

19. WHO. Quantification of health effects of exposure to air pollution: report on a WHO working group, Bilthoven, Netherlands 20-22 November 2000. 2001, Copenhagen: WHO Regional Office for Europe.

20. Alizadeh H, Mohammadi M. Evaluation of Urban Security Components based on Structuralist approach-Case Study: Urmia City. Sci Res Q. 2018;26(104):145-158

21. Gholampour A, Nabizadeh R, Naseri S, Yunesian M, Taghipour $\mathrm{H}$, Rastkari N, et al. Exposure and health impacts of outdoor particulate matter in two urban and industrialized area of Tabriz, Iran. J Environ Health Sci. 2014;12(1):27. Eng

22. Naddafi K, Hassanvand MS, Yunesian M, Momeniha F, Nabizadeh R, Faridi S, et al. Health impact assessment of air pollution in megacity of Tehran, Iran. J Environ Health Sci Eng. 2012;9(1):28.

23. Fattore E, Paiano V, Borgini A, Tittarelli A, Bertolid M, Crosignani $P$, at el. Human health risk in relation to air quality in two municipalities in an industrialized area of Northern Italy. Environ Sci Pollut Res. 2011;111(8):1321-1327.

24. Rezaei Kalantari R, Kermani M, Dowlati M, Jonidi Jafari A. Number of mortality, chronic obstructive pulmonary disease and acute myocardial infarction due to exposure to sulfur dioxide in Tehran, during 2005-2014. Koomesh. 2018;20(1):34-42.

25. Kamarehie B, Ghaderpoori M, Jafari A, Karami M, Mohammadi A, Azarshab K, et al. Estimation of health effects (morbidity and mortality) attributed to PM10 and PM2. 5 exposure using an Air Quality model in Bukan city, from 2015-2016 exposure using air quality model. Environ Health Eng Manag. 2017;4(3):137-142.

26. Kianisadr M, Ghaderpoori M, Jafari A, Kamarehie B, Karami MA. Zoning of air quality index (PM10 and PM2. 5) by Arc-GIS for Khorramabad city, Iran. Data Brief. 2018;19:1131-1141.

27. Kermani M, Dowlati M, Jonidi Jafari A, Rezaei Kalantary R. The association of hospital emergency admissions due to respiratorycardiovascular diseases and acute myocardial infarction with air pollution in Tehran during 2005-2014. Med J Islam Repub Iran. 2018 Aug 26;32:76.

28. Ghozikali MG, Mosaferi M, Safari Gh, Jaafari J. Effect of exposure to $\mathrm{O} 3$, NO 2, and SO 2 on chronic obstructive pulmonary disease hospitalizations in Tabriz, Iran. Environ Sci Pollut Res. 2015;22(4):2817-2823.

29. Motalleby M, Mazaheri A, Mosayebi M, Takhtfiroozeh SM. Assessing Health Impacts of Air Pollution in Kashan 2011. Arak Med Uni J. 2015;18(98):77-87.

30. Committee HIO. Health effects of outdoor air pollution in developing countries of Asia: A literature review. Health Effects Institute, Boston, USA, 2004

31. Aga E, Samoli E, Touloumi G, Anderson HR, Cadum E, Forsberg B, et al. 
Short-term effects of ambient particles on mortality in the elderly: results from 28 cities in the APHEA2 project. Eur Respir J Suppl. 2003 May;40:28s-33s.

32. Samet JM, Zeger SL, Dominici F, Curriero F, Coursac I, Dockery DW, et al. The national morbidity, mortality, and air pollution study. Part II: morbidity and mortality from air pollution in the United States. Res Rep Health Eff Inst. 2000;94(pt 2):5-79.

33. Ghozikali MG, Mosaferi M, Safari Gh, Jaafari J. Effect of exposure to

$\mathrm{O}_{3}, \mathrm{NO}_{2}$, and $\mathrm{SO}_{2}$ on chronic obstructive pulmonary disease hospitalizations in Tabriz, Iran. Environ Sci Pollut Res. 2015;22(4):2817-2823. 